\title{
Simulation for Technical and Economical Evaluation of Thermal Energy Storage in CSP Systems
}

\author{
Umesh Ramamoorthi $^{\# 1}$, Axel Gottschalk ${ }^{* 2}$ \\ ${ }^{\# 1,2}$ Institute of Process Engineering, Bremerhaven University of Applied Sciences \\ An der Karlstadt 8, 27568, Bremerhaven. Germany \\ ${ }^{1}$ uramamoorthi2@hs-bremerhaven.de \\ 2agottschalk@hs-bremerhaven.de
}

\begin{abstract}
Thermal energy storage systems can store heat or cold to be used under various conditions such as temperature, place or power. The main use of thermal energy storage systems is to overcome the mismatch between the generation and usage. Large-scale thermal energy storage is widely used today. It has become a commercially used technology in solar power plants. In a concentrated solar power system (CSP), there is always the availability of huge thermal energy to be stored. A solar power tower system, which is a type of concentrating solar power (CSP), is simulated with the SAM (System Advisor Model) in this work. Along with it, an in-house custom model is developed that is coupled with the System Advisor Model (SAM) including thermal energy storage through a rigorous simulation. In this work, two types of thermal energy storages for the CSP plants are simulated. The first type is the classic two-tank storage system, which is a sensible heat storage system with molten salt. The second type used in this work is latent heat storage. Since there is no commercial availability of a latent heat storage system yet for a CSP tower system, their cost is predominantly assumed here from published literature sources. From this model, a large data set of economical insights is generated such as installed costs, equipment costs, capacity factor net capital costs of the plant, net cost of the two-tank storage unit and the latent heat storage unit. The results from such a technical and economical evaluation guide decision makers towards meaningful investments in innovative technologies.
\end{abstract}

Keyword- Thermal Energy Storage, Concentrated Solar Power, Latent Heat Storage, Renewable Energy

\section{INTRODUCTION}

Concentrating solar thermal power, more commonly referred to as CSP, is unique among renewable energy generators because even though it is variable, like solar photovoltaic and wind, it can easily be coupled with thermal energy storage (TES) as well as conventional fuels [1]. This is one of the main reasons to show how a CSP is a better option to design thermal energy storage system for a beginner. Energy storage reduces the necessity of extra equipment during peak times by energy storage during off peak times [2]. This is one of the reasons why thermal energy storage is advantageous. Moreover, it gives a flexibility to dispatch the power produced by helping us to store it. Predominantly, CSP is coupled with a sensible or a latent heat thermal energy storage system. A sensible storage involves heating materials without causing a phase change in it while latent heat storage causes a phase change of the material while heating or cooling. The amount of energy stored in the sensible storage depends on the specific heat, the temperature change and the amount of material. It is represented through the following equation.

$$
Q=\int_{T_{i}}^{T_{f}} m C_{p} d T=m C_{a p}\left(T_{f}-T_{i}\right)
$$

As storing the latent heat alone in a material is impossible, the material has to undergo a sensible heating to reach the point where the phase change occurs. Hence, the latent heat storage could be represented by the following equation.

$$
\begin{aligned}
& Q=\int_{T_{i}}^{T_{m}} m C_{p} d T+m a_{m} \Delta h_{m}+\int_{T_{m}}^{T_{f}} m C_{p} d T \\
& Q=m\left[C_{s p}\left(T_{m}-T_{i}\right)+a_{m} \Delta h_{m}+C_{l p}\left(T_{f}-T_{m}\right)\right]
\end{aligned}
$$

In the above equation, the first term represents the sensible heat stored by the material where the temperature increases from its initial temperature to its phase change temperature. The second term represents the energy stored by the material during its phase change. If the material is further heated, the third term comes in to picture, which is again sensible heat storage [3]. 


\section{Simulation AND Creating a Model to InCorporate ThERMAL ENERgy StORAgE IN CSP}

As stated in [4], addition of thermal energy storage would increase the cost of the CSP, while there is an advantage of increased capacity factor of the plant. An in-house model coupled with SAM (System Advisor Model) is created in the previous work of us [5] to calculate the turbine output, total capital costs and total installations costs for various cases of thermal energy storage. A rigorous simulation that can generate a vast set of relevant data is the first step towards analysis and later optimization.

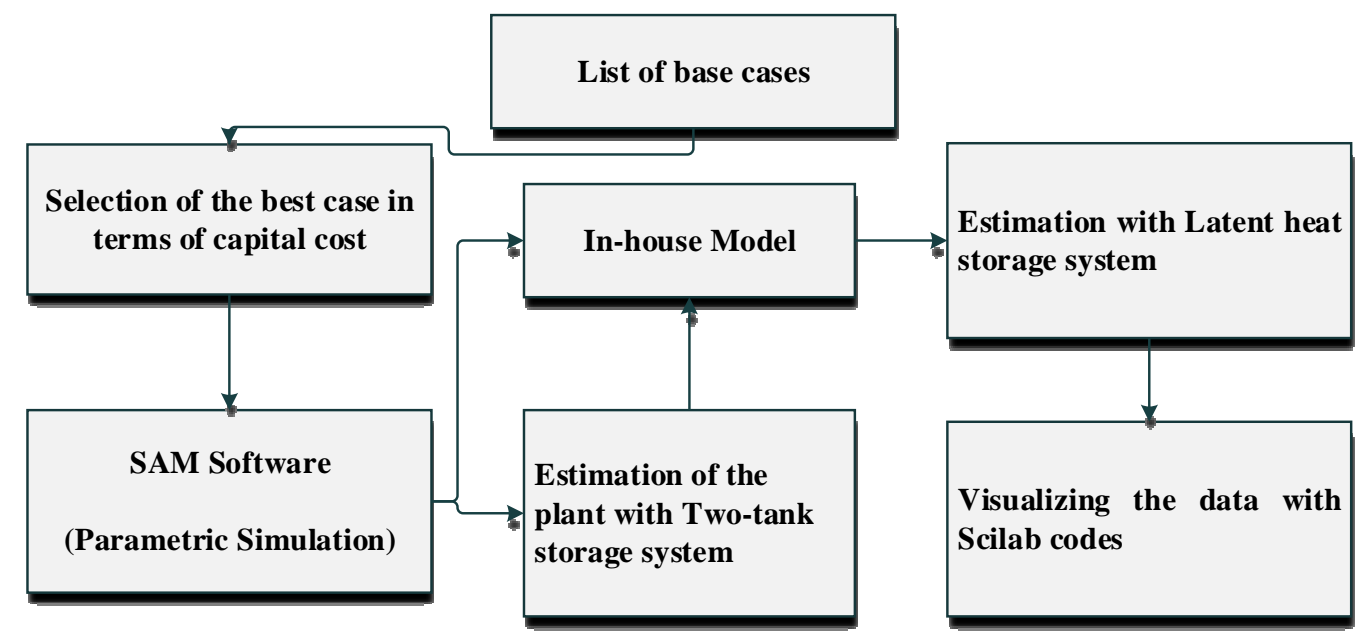

Figure 1 Steps involved in the building of the model

Initially, a huge set of base cases are generated which is compiled in the work of [5]. Out of which the best case in terms of the least capital cost is chosen for a parametric simulation. The results of the parametric simulation are fed in to the in-house model, which is then used in estimating the two-tank storage and latent heat storage systems coupled with the CSP (Figure 1). Since, the results are an interlinked function of more than two parameters, in most cases three, a Scilab code is written to represent the data in the form of a surface. The building up of surface plots and the inter-relationships of the parameters are done to build a platform for the development of determining a way through optimization in the upcoming work.

\section{III.RESULTS AND DISCUSSION}

As per [4], the investment cost for the solar power tower plants without a storage system falls in-between 4.5 $7.15 \$ / \mathrm{kW}$. Addition of a thermal energy storage system effectively increases the investment cost, which is evidently depicted in the Figure 2. The lower limit of $4.5 \$ / \mathrm{kW}$ is the red surface at the bottom and the light blue surface of $7.15 \$ / \mathrm{kW}$ is above it. In addition, the top layer in thick blue represents the net capital cost with thermal energy storage. This layer peaks the net capital cost ( $\mathrm{Z}$ axis) when the thermal energystorage hours reaches the maximum of 10 hours (Y-axis).

The lower limit and upper limit surfaces have no thermal energy storage system, but they are plotted as a surface simply to compare them with the surface (in blue at the top) of thermal energy storage system.

When this is compared with the graph of capacity factor in Figure 4, the capacity factor obviously peaks as the thermal energy storage hours increases (Y-axis). However, it is also to be observed that the peak capacity factor is not formed at the maximum turbine output (X-axis). Hence, this opens up a possibility of optimizing between the capacity factor and turbine output, which would invariably affect the net capital cost per watt.

In a similar way, a three dimensional plot has been formed with the three parameters of turbine output, thermal energy storage hours and total installed costs (Figure 3). The surface in the red denotes the thermal energy storage with a two-tank system while the blue surface denotes the thermal energy storage system that can store as latent heat. 


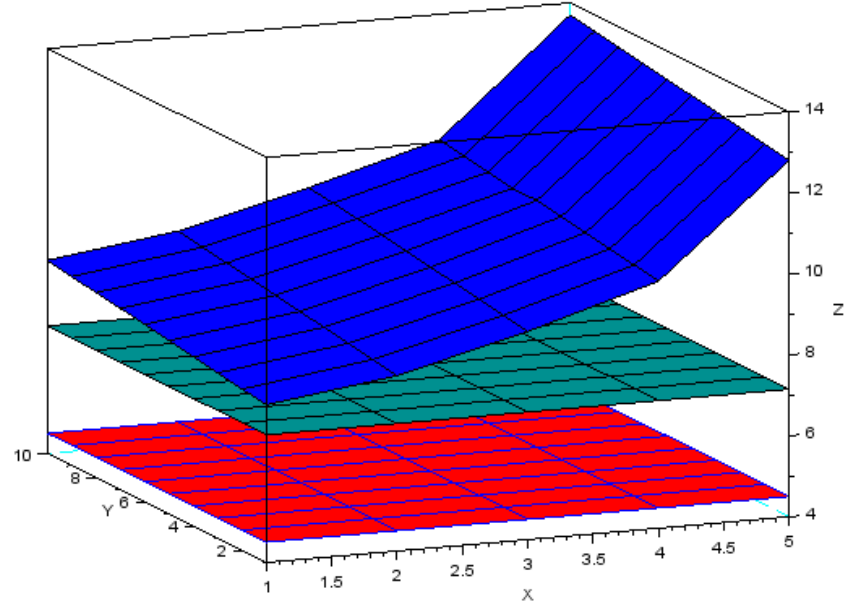

Figure 2 the above figure is a three dimensional relationship between the parameters of the following: $\mathrm{X}$-axis = multiples of turbine output (X20 MWe); Y-axis = Load hours of thermal energy storage (hours); Z-axis = Net capital cost per watt $(\$ / W)$. The red surface denotes lower limit of the net capital cost per watt without storage. The light blue surface denotes upper limit of the net capital cost per watt without storage. The blue surface at the top represents the net capital cost with two-tank storage system.
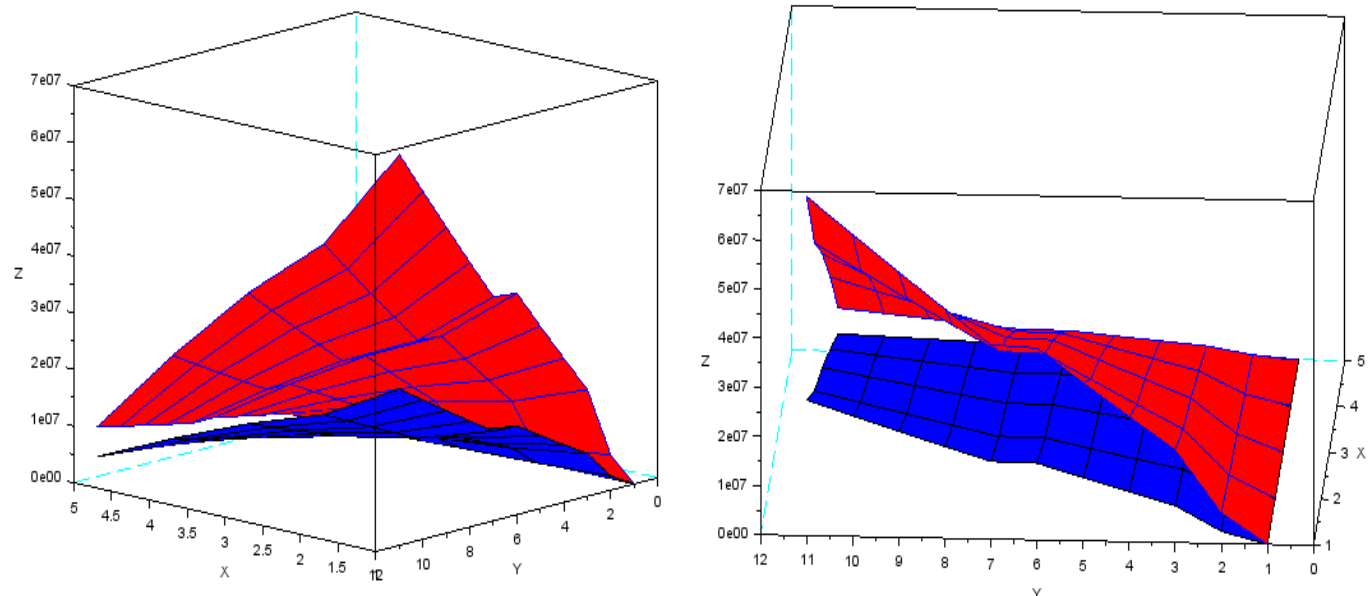

Figure 3 the above figure is a three dimensional relationship between the parameters of the following: $\mathrm{X}$-axis = multiples of turbine output (X20 MWe); Y-axis = Load hours of thermal energy storage (hours); Z-axis = Contribution of energy storage costs in the total installed costs (\$). The red surface denotes the thermal energy storage in Two-tank system. The blue surface denotes the latent heat thermal energy storage.

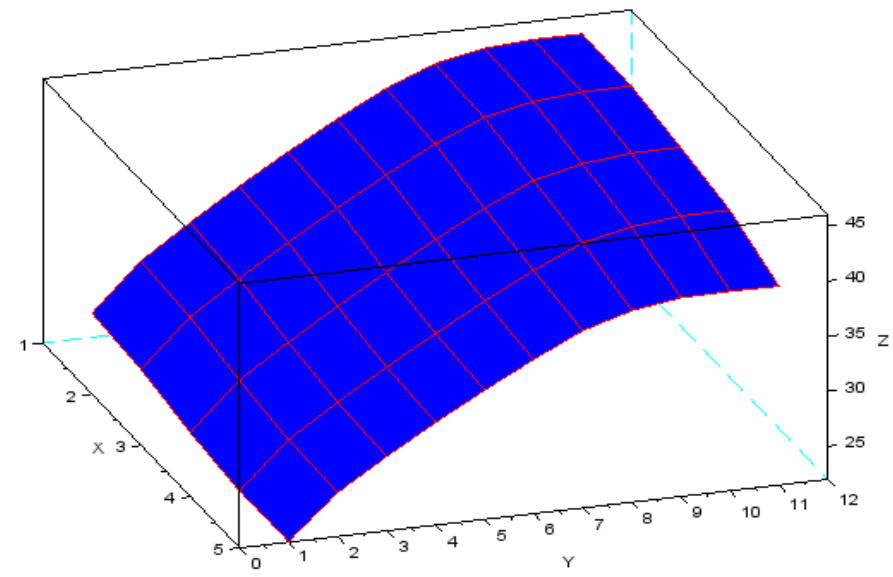

Figure 4 the above figure is a three dimensional relationship between the parameters of the following: $\mathrm{X}$-axis = multiples of turbine output (X20 MWe); Y-axis = Load hours of thermal energy storage (hours); Z-axis = Capacity factor 
Both the surfaces start together in Error! Reference source not found.. They both peak the contribution of energy storage in total installed costs (Z-axis) when the load hours of the thermal energy storage (Y-axis) is maximum. On the other hand, the surface is twisted in many ways before reaching the maximum value in $\mathrm{Z}$-axis, which opens the door to optimization depending on the requirements for running the process. One of the inferences from this surface plots is, that the latent heat storage systems are relatively cheaper in their contribution to the total installed cost compared to the two-tank systems. While developing the in-house model for this, the cost evaluation data published in [6] is used as a basis.

\section{IV.CONCLUSION}

The in-house model developed is a product of interlinked functions of several parameters, which could be plotted as a surface. These interlinked functions are developed through the generation of huge data sets. These data sets in-turn form the platform in choosing the optimized version of running a CSP process with or without thermal energy storage system. While comparing the two-tank storage system with latent heat storage system, a latent heat storage could save the installation costs relatively. This is also substantiated by [7], which states that the two-tank system is the state of the art in this application area. While this offers a low technical risk, the potential for cost reduction is also low in this. Innovative storage concepts are required to bring down the costs of the two-tank storage systems, which could be a low cost solid storage media. The application of phase change materials is an attractive solution here. The reason for it being the reduced cost of a latent heat storage system and the less space required by it for the construction in comparison with a sensible heat storage system. However, the economical insights of how effectively a latent heat storage system with phase change materials would work on its integration are to be taken in to account. In that sense, the surface plots show the order in which the cost of latent heat storage may differ in its contribution to the total installed costs compared to the two-tank storage systems. It also concludes that a latent heat storage system could be economical compared to the existing sensible heat storage systems.

\section{ACKNOWLEDGMENT}

The author would like to acknowledge the support of The German Federal Ministry of Education and Research (Bundesministerium für Bildung und Forschung, BMBF) for financial support under project INOTES (No 01DQ14009) within the New Indigo ERANET funding scheme.

\section{REFERENCES}

[1] S. Kuravi, J. Trahan, D. Y. Goswami, M. M. Rahman and E. K. Stefanakos, "Thermal energy storage technologies and systems for concentrating solar power,” Progress in Energy and Combustion Science, pp. 285-319, 2013.

[2] B. Zalba, J. B. Marin, F. Luisa, Cabiza. and H. Mehling, "Review on thermal energy storage with phase change: materials, heat transfer analysis and applications,” Applied Thermal Engineering, pp. 251-283, 2003.

[3] B. Cárdenas and N. León, "High temperature latent heat thermal energy storage: Phase change materials, design considerations and performance enhancement techniques,” Renewable and Sustainable Energy Reviews, no. 27, p. 724-737, 2013.

[4] IRENA, RENEWABLE ENERGY TECHNOLOGIES: COST ANALYSIS SERIES - Concentrated Solar Power, The International Renewable Energy Agency (IRENA), 2012.

[5] U. Ramamoorthi and A. Gottschalk, "Parametric simulation and economic estimation of Thermal Energy Storage in Solar Power Tower," in Conference on Processing of Materials, Minerals and Energy. Materials Today: Proceedings - Journal - Elsevier, Andhra Pradesh, India, 2016.

[6] C. Smith, Y. Sun, B. Webby, A. Beath and F. Bruno, "Cost analysis of high temperature thermal energy storage for solar power plant," Australian Solar Energy Society, 2014.

[7] L. F. Cabeza, Advances in Thermal Energy Storage Systems: Methods and Applications, Cambridge, United Kingdom: Elsevier Woodhead Publishing Series in Energy: Number 66, 2015.

\section{AUTHOR PROFILE}

Umesh Ramamoorthi: Researcher - Institute of Process Engineering. M.Sc Process Engineering and Energy Technology

Prof. Dr.-Ing. Axel Gottschalk: Director - Institute of Process Engineering. 